\title{
The Influence of Stratospheric Wave Reflection on North American Cold Spells $\mathscr{O}$
}

\author{
VIVIEN MATthiAS $^{\mathrm{a}}$ AND MARLENE KRETSCHMER ${ }^{\mathrm{b}}$ \\ Potsdam Institute for Climate Impact Research, Potsdam, Germany
}

(Manuscript received 11 October 2019, in final form 30 December 2019)

\begin{abstract}
Understanding and predicting midlatitude cold spells is of scientific and public interest, given often associated severe impacts. However, large-scale atmospheric dynamics related to these events are not fully understood. The winter of 2017/18 was characterized by several cold spells affecting large parts of North America and Eurasia. Here, the role of stratosphere-troposphere coupling for the occurrence of cold spells in this winter is investigated using different wave propagation diagnostics. While the European cold spell in late February 2018 was influenced by a major sudden stratospheric warming (SSW) associated with wave absorption, the cold spells over North America at the end of December 2017 and early February 2018 were related to downward reflected waves over the North Pacific. Previously proposed wave reflection indices, however, either miss these reflection events or are not able to distinguish them from the major SSW related to wave absorption. To overcome this, a novel simple index based on eddy heat flux is proposed here, capturing regional wave reflection over the North Pacific. Reflection events detected with this index are shown to be followed by North Pacific blocking and negative temperature anomalies over North America. An improved understanding of the contribution of wave reflection for cold spells is crucial to better predict such events in the future.
\end{abstract}

\section{Introduction}

Winter cold spells in the densely populated midlatitudes can cause significant economic and societal damages. In recent years, several extremely cold winters were observed, with severe impacts for the energy, health, and transportation sectors (Palmer 2014; Cohen et al. 2014, 2018; Analitis et al. 2008). The boreal winter of 2017/18 was related to high-impact, cold spell events: At the end of December 2017, a cold wave brought frigid temperatures to large parts of Alaska, Canada, and

\footnotetext{
${ }^{1}$ The New York Times, 2018: It's So Cold That. Accessed 28 July 2019, https://www.nytimes.com/2018/01/02/us/its-so-cold-that.html.
}

Supplemental information related to this paper is available at the Journals Online website: https://doi.org/10.1175/MWR-D-190339.s1.

\footnotetext{
${ }^{\text {a }}$ Current affiliation: German Aerospace Center (DLR), Neustrelitz, Germany.

${ }^{\mathrm{b}}$ Current affiliation: University of Reading, Reading, United Kingdom.
}

Corresponding author: Vivien Matthias, vivien.matthias@dlr.de the northeastern United States, breaking decades-long minimum temperature records. ${ }^{1}$ In early February, the same regions suffered from another cold spell, while the western United States was exceptionally warm. ${ }^{2}$ Later that month, Europe was hit by the so-called beast from the east, ${ }^{3}$ an anticyclone transporting cold Arctic air to European midlatitude regions, causing several cold-related fatalities.

Given the pronounced impacts for societies, understanding the atmospheric circulation patterns and mechanisms associated with midlatitude cold spells is important. These events usually coincide with high-latitude blocking, causing advection of cold Arctic air downstream (Linkin and Nigam 2008; Woollings 2010; Yao et al. 2017; Messori et al. 2016; Pithan et al. 2018). However, the location and underlying drivers of the formation of

\footnotetext{
${ }^{2}$ The Weather Channel, 2018: Is This Really February in California? All-Time Record Highs are Being Set, accessed 28 July 2019, https://weather.com/news/weather/news/2018-02-06-februaryin-california-all-time-record-highs-set.

${ }^{3}$ The Telegraph, 2018: U.K. weather: Snow warnings as "beast from the East" grips Britain and "postpones"' spring, accessed 28 July 2019, https://www.telegraph.co.uk/news/ 2018/02/23/uk-weather-snow-warning-london-south-east-beasteast-grips-britain/.
} 
winter blocking can be manifold (Baxter and Nigam 2015; Palmer and Owen 1986; Chen and Luo 2017; Handorf et al. 2015; Vihma 2014; Cohen et al. 2014; Smith et al. 2010). One well-documented driver of high-latitude blocking and severe winter weather in the midlatitudes is the stratospheric polar vortex (hereafter also just referred to as polar vortex or vortex). It describes a band of fast westerly winds in the Arctic stratosphere, forming in boreal winter due to the thermal wind relation and the rapid cooling of the high-latitude Arctic in the polar night (Waugh et al. 2017). Troposphere-induced upwardpropagating planetary waves can interact with the stratospheric flow, this way contributing to the large intraseasonal variability in vortex strength (Polvani and Waugh 2004; Matsuno 1971; Dunn-Sigouin and Shaw 2015). In return, the strength of the stratospheric polar vortex can also influence tropospheric circulation and has in particular been related to extreme winter weather (Baldwin and Dunkerton 2001; Kolstad et al. 2010; Woollings et al. 2010; Kidston et al. 2015; Kretschmer et al. 2018a). Although the exact mechanisms are not fully understood, there are mainly two different forms of downward coupling between the stratosphere and the troposphere.

First, under certain favorable conditions, the polar vortex can absorb upward-propagating planetary waves, leading to a weakening of the stratospheric zonal-mean zonal flow (Polvani and Waugh 2004; Matsuno 1971; Kodera et al. 2016). In the most extreme cases, so-called major sudden stratospheric warmings (SSWs), the winds encompassing the vortex reverse to easterly (Butler et al. 2014; Scherhag 1952). Via subsequent downward propagation of the circulation anomalies, SSWs can then affect tropospheric circulation for up to two months (Baldwin and Dunkerton 2001; Hitchcock and Simpson 2014). This influence is usually described in terms of a downward-descending negative phase of the northern annular mode (NAM), respectively, a negative North Atlantic Oscillation (NAO) at the surface, and is strongly associated with cold spells over the Eurasian continent (Kretschmer et al. 2018a; Garfinkel et al. 2017; Kretschmer et al. 2018b). Although some SSWs do not affect the troposphere below (Karpechko et al. 2017), the potential of SSWs to produce cold spell over Eurasia has been robustly shown by a range of studies (Baldwin and Dunkerton 2001; Kolstad et al. 2010; Kretschmer et al. 2018a; Garfinkel et al. 2017; Hitchcock and Simpson 2014). Consistently, operational forecast models show improved skills in predicting midlatitude weather when initialized during SSWs (Sigmond et al. 2013; Scaife et al. 2016).

Second, the polar vortex can also act as a reflective surface, preventing the absorption of upwardpropagating waves. Troposphere induced waves entering the stratosphere are then reflected downward, thereby influencing tropospheric circulation (Harnik 2009; Shaw et al. 2010; Perlwitz and Harnik 2004; Kodera et al. 2008, 2013). While the occurrence of wave reflection is well documented (Perlwitz and Harnik 2003; Shaw et al. 2010; Nath et al. 2014), its impacts on surface weather have been given less attention. Recently, Kretschmer et al. (2018a) showed that downward reflected waves over Canada favor North Pacific blocking, respectively, a negative phase of the Western Pacific Oscillation (WPO), and are associated with cold spells over Canada and the northeastern United States, consistent with earlier case studies (Kodera et al. 2008, 2013). Nevertheless, the exact role of wave reflection for North American cold spells, as well as the possibilities for subseasonal to seasonal (S2S) forecasting has not yet been comprehensively assessed.

One reason why reflection events have been given less attention in the past is that (in constrast to the detection of SSWs), no straightfoward index exists to describe them. Wave reflection occurs when a vertically bounded meridional waveguide forms in the high-latitude stratosphere (Perlwitz and Harnik 2003; Shaw et al. 2010). Thus, both the formation of a vertical reflecting surface as well as the formation of a meridional waveguide that channels the reflected waves downward are necessary. Different approaches to detect wave reflection have been used in the literature, which are yet subject to several limitations. On the one hand, analyzing the evolution of daily wave activity fluxes (Plumb 1985; Kodera et al. 2008, 2013; Nath et al. 2014) or using the zonal mean wave geometry diagnostic developed by Harnik and Lindzen (2001) is insightful, yet, their computation is rather time consuming and the required data are usually not a standard output of reananylsis produts or climate models. On the other hand, Perlwitz and Harnik (2003) proposed a simple reflection index as the difference of the zonalmean zonal wind at 2 and at $10 \mathrm{hPa}\left(\bar{U}_{2-10}\right)$ averaged over $58^{\circ}-74^{\circ} \mathrm{N}$ and over winter season. A negative (positive) $\bar{U}_{2-10}$ index indicates negative (positive) vertical wind shear in the stratosphere and corresponds to reflective (nonreflective) basic state of the polar vortex for a considered winter. However, as wave reflection events and major SSWs (related to wave absorption) can occur in the same winter (Kodera et al. 2013; Kretschmer et al. 2018a), seasonal means at least partly dilute the different surface signals. As an extention, Nath et al. (2016) introduced a daily resolved version of the $\bar{U}_{2-10}$ index. However, both versions of this index are always negative during SSWs (Harnik 2009) and thus generally not suitable to distinguish between SSWs and wave reflection. Another limitation of the $\bar{U}_{2-10}$ index is that it is based on zonal-mean values only. Nath et al. (2014) showed that longitudinal variations in the stratosphere 
can have an impact on regional weather extremes and therefore extended the $\bar{U}_{2-10}$ index in the longitude direction $\left(U_{2-10}\right)$, introducing the concept of a partially reflective stratospheric background state (Nath et al. 2016). Nevertheless, the negative values during SSWs remain as an issue.

Here, we will first discuss the stratospheric influence on the above described cold spells in winter 2017/18. While the European cold spell in late February 2018 was influenced by a downward-propagating NAM after a major SSW, the two North American cold spells in December 2017 and early February 2018 were influenced by stratospheric regional wave reflection over the North Pacific. We show that these regional wave reflection events would not have been detected by the zonal mean $\bar{U}_{2-10}$ index. Therefore, we introduce a novel regional reflection index based on meridional eddy-heat fluxes at $100 \mathrm{hPa}$, capturing wave reflection events over the North Pacific. This new index is easy to compute, can distinguish between wave reflection events and SSWs and is associated with cold spells over North America approximately 10 days after its onset. Finally, we discuss the potential of this novel index for the prediction of the occurrence and duration of cold spells over North America.

\section{Data and methods}

Our study focuses on the winter period from December 2017 to March 2018. We use daily ERA-Interim data (Dee et al. 2011) provided on a $0.75^{\circ} \times 0.75^{\circ}$ grid on 37 vertical levels from 1000 to $1 \mathrm{hPa}$. The analyses are based on daily mean data. Climatological anomalies are calculated by removing the multiyear mean during 1979-2019 of each day. To further remove short-term fluctuations we calculate 5-day running means when considering the temporal evolution of a parameter over the course of the winter and a 3-day mean otherwise.

To assess the location and intensity of high-latitude blocking, we follow Kodera et al. (2013) and use the blocking index based on Tibaldi and Molteni (1990). This index is based on meridional gradients of geopotential height at $500 \mathrm{hPa}$ calculated at each longitude (Tibaldi and Molteni 1990). Roughly speaking, blocking is detected at a certain longitude if the meridional geopotential height gradient becomes negative at high latitudes and positive at midlatitudes. We note, however, that this estimation has a known bias to underrepresent blocking in the Pacific region due to the latitude restriction in the calculation of the metric (Tibaldi and Molteni 1990).

The strength of the stratospheric polar vortex is calculated as the zonal-mean zonal wind at $10 \mathrm{hPa}$ and $60^{\circ} \mathrm{N}$. Following previous studies, the first day this index becomes negative is defined as the central date of a major SSW (Polvani and Waugh 2004; Butler et al. 2014). As a proxy for vertical wave activity fluxes we further compute poleward eddy heat fluxes at $100 \mathrm{hPa}$ averaged over $45^{\circ}-75^{\circ} \mathrm{N}$. The northern annular mode (NAM) is approximated by averaging geopotential heights over the polar cap $\left(60^{\circ}-90^{\circ} \mathrm{N}\right)$, which is tightly linked to the NAM index defined by the empirical orthogonal function (Karpechko et al. 2017; Baldwin and Thompson 2009).

To investigate the propagation of planetary waves we show the vertical profile of eddy geopotential heights (i.e., with the zonal mean being removed at each longitude), where westward (eastward) tilt with height is indicative of upward (downward) propagation of the wave packet. This analysis is complemented by considering the quasigeostrophic version of the wave activity flux (WAF) in spherical coordinates [Eq. (7.1) of Plumb (1985)] also known as Plumb flux. To keep consistency with Wentzel-Kramers-Brillouin (WKB) assumptions used in the derivation of the wave activity flux (Plumb 1985) both quantities have been first filtered for wavenumbers $1-3$ and have then been averaged over a period of 3 days to remove short-term variability. This way we might not always fullfill the WKB approximation but can nevertheless use the WAF in a qualitative way.

To check for wave reflection conditions as described by (Perlwitz and Harnik 2004), the curvature $\kappa$ of the vertical and meridional zonal wind profile is calculated by

$$
\kappa=\frac{u^{\prime \prime}}{\left(1+u^{\prime 2}\right)^{3 / 2}},
$$

where $u$ is the zonal wind; and ( $)^{\prime}$ and ( $)^{\prime \prime}$ are the first and second derivative in vertical or meridional direction, respectively. Increased values of curvature are defined as values exceeding the mean value.

\section{Results}

In this section we first discuss the role of stratospheretroposphere coupling for the cold spells in winter 2017/18 in detail (section 3a). In particular, we show that both wave reflection and wave absorption (related to a major SSW) were key factors for the occurrence of the negative temperature anomalies. Next, we study wave reflection in more detail (section $3 b$ ). In this context we discuss general challenges and limitations of existing wave reflection indices, keeping the example of the winter 2017/18. Finally, we propose a novel regional 


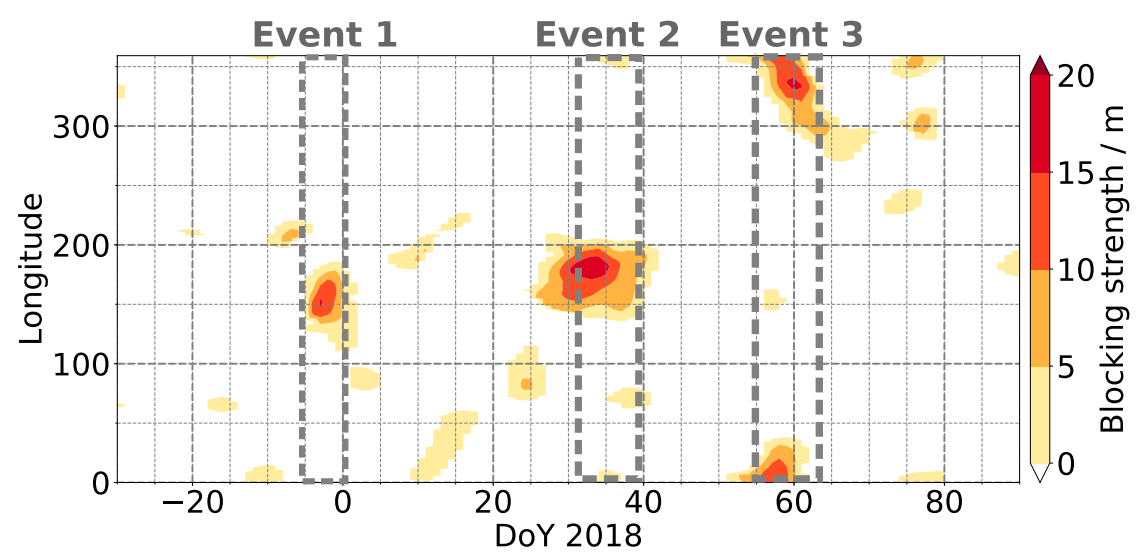

FIG. 1. Hovmöller diagram of the high-latitude blocking strength (see section 2) in the winter 2017/18.

reflection index that overcomes these limitations and strongly projects onto cold spells in North America.

a. Midlatitude cold spells in winter 2017/18

\section{1) Detection of MidLATitude COLD SPELlS BASED ON BLOCKING}

Figure 1 shows the location and strength of highlatitude blocking over the course of the winter 2017/18. There are three strong blocking events here indicated by the dotted gray lines. The first event occurred at the end of December 2017 in the northwestern Pacific around $160^{\circ} \mathrm{E}$. The second and even more pronounced blocking pattern regarding spatial extent, duration, and magnitude, occurred at the end of January and beginning of February 2018 in the northern Pacific around $180^{\circ}$ and thus slightly eastward shifted compared to event 1 . The last high-latitude blocking event started at the end of February 2018 stretching from approximately $50^{\circ} \mathrm{E}$ to $60^{\circ} \mathrm{W}$.

All three blocking events were associated with continental-scale negative temperature anomalies (here referred to as cold spell) downstream (Fig. 2). The first event was associated with anomalously negative temperatures in Alaska and over large parts of Canada and the northeastern United States. This is consistent with the detected blocking over the North Pacific sector, causing advection of cold Arctic air downstream (e.g., Linkin and Nigam 2008). Later that winter (event 2, Fig. 2b), a similar temperature pattern was observed over North America that coincided with the even stronger blocking pattern in this area. At the end of the month, during event 3 (Fig. 2c), most of Europe was exceptionally cold, related to negative NAO-like geopotential height anomalies over the North Atlantic (not shown). In summary, the winter of 2017/18 was thus characterized by persistent phases of high-latitude blocking both in the Pacific and Atlantic sector that were associated with cold spells downstream of these patterns.

\section{2) THE ROLE OF STRATOSPHERE-TROPOSPHERE COUPLING DURING THE EVENTS}

As outlined in the introduction, stratospheric variability can affect tropospheric blocking and thus midlatitude weather (Baldwin and Dunkerton 2001; Woollings et al. 2010; Kidston et al. 2015). In the following, we will therefore assess the potential role of stratosphere-troposphere coupling for each of the three different cold spell events and the associated blocking patterns. For this purpose, we plot the temporal evolution of the absolute (Fig. 3a, blue line) and anomalous strength (Fig. 3a, red line) of the stratospheric polar vortex (defined at $10 \mathrm{hPa}$ ) in the winter 2017/18. Moreover, we show the lower-stratospheric (at $100 \mathrm{hPa}$ ) poleward eddy heat fluxes (Fig. 3b) and the NAM index over different tropospheric and stratospheric levels (Fig. 3c). To diagnose wave propagation beyond these zonal-mean metrics, we further compute the zonal and vertical components of the wave activity fluxes before and during each of the three different events (Figs. 4-6).

\section{(i) Event 1: The North American cold spell in December 2017}

Before the onset of the first North American cold spell (event 1), the polar vortex was relatively weak with anomalies below one standard deviation (std) but strengthened ( $>1 \mathrm{std}$ ) during the event (Fig. 3a), consistent with the anomalously high heat fluxes $(>1 \mathrm{std}$, Fig. 3b) before the event and anomalously low heat fluxes $(<2$ std, Fig. 3b) during the event. This is also represented by the NAM index in the stratosphere, 
Event 1

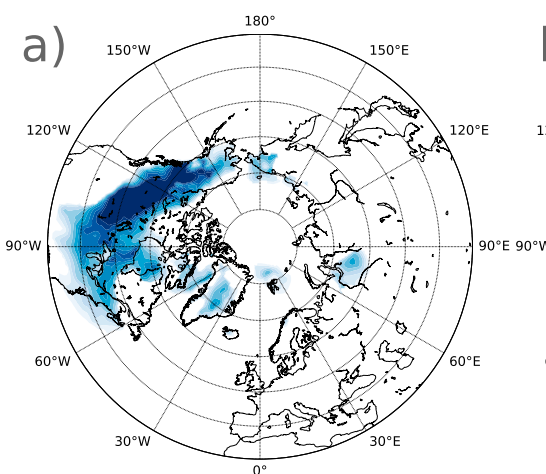

Event 2

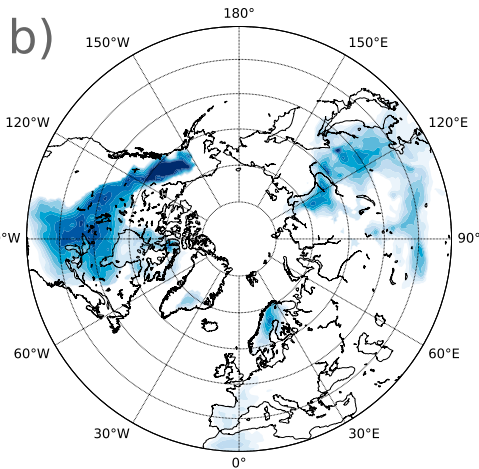

\section{Event 3}

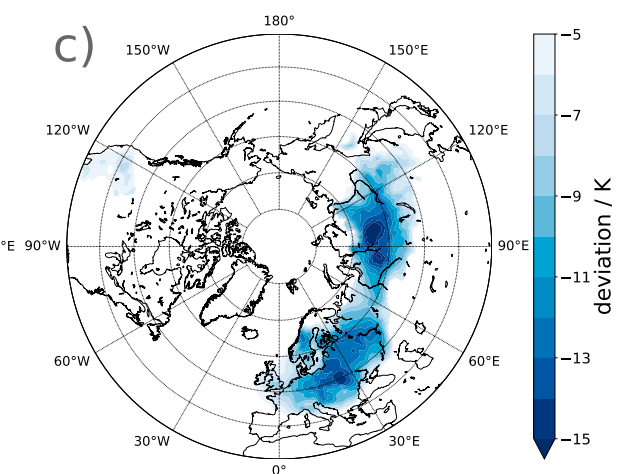

FIG. 2. Temperature anomalies averaged over different periods in the winter 2017/18, (a) from 26 to 31 Dec (event 1 ), (b) from 2 to $8 \mathrm{Feb}$ (event 2), and (c) from $24 \mathrm{Feb}$ to 4 Mar (event 3). For visualization purposes only areas that exceed one standard deviation are shown.

switching from negative to positive phase during event 1 (Fig. 3c). Nine days before event 1, the height-longitude cross sections of the wave activity fluxes (Fig. 4a, arrows) reveal a wave train stretching from the Eurasian sector in the troposphere $\left(50^{\circ}-100^{\circ} \mathrm{E}\right)$ to the Aleutian region in the stratosphere $\left(180^{\circ}-260^{\circ} \mathrm{E}\right)$. Consistently, the vertical phase tilt of the eddy geopotential height is westward in these regions (Fig. 4a, contour lines) representing upward propagation of waves. At approximately $30 \mathrm{~km}$ height, when the waves reached the positive eddy geopotential heights over the North Pacific, they stopped propagating upward but instead descended and propagated downward (see eastward phase tilt of eddy geopotential height, Fig. 4a). Note that in the Eastern Hemisphere a part of the wave packet was still upward propagating. This indicates some kind of bifurcation of the wave packet in the upper stratosphere characterized by an upward propagation in the Eastern Hemisphere and downward propagation in the Western Hemisphere. This becomes also evident by the spatial patterns of the vertical component of the wave activity fluxes at $100 \mathrm{hPa}$ level (at about $16 \mathrm{~km}$ altitude), showing upward wave propagation over the North Pacific and downward wave propagation over Canada (Fig. 4b). A few days later, roughly 4 days before the event started, the lowerstratospheric upward-pointing wave activity fluxes intensified over the Eurasian and North Pacific sectors and also the downward wave propagation over Canada enhanced (Figs. 4c,d) that peaked during event 1 (Figs. 4e,f). In agreement with the downward-propagating waves, the positive eddy geopotential heights over the North Pacific sector, first only observed in the stratosphere above $10 \mathrm{~km}$ height (Fig. 4a), descended down into the troposphere (Figs. 4c,e), where they coincided with the detected blocking pattern in this region [Fig. 1; see also Kodera et al. (2013)].
The observed patterns of wave propagation are hence overall consistent with the wave reflection mechanism described by (Kodera et al. 2008, 2013) and the surface impacts studied in Kretschmer et al. (2018a). As can be seen in the WAF plots in Fig. 4, the regions of upward and downward propagation of the planetary waves are distinct, indicating wave reflection. To cross check this finding, we further computed the zonal mean EliassenPalm (EP) flux (Edmon et al. 1980), which confirmed the occurrence of downward propagation below $20 \mathrm{~km}$ and northward of $60^{\circ} \mathrm{N}$ (see Fig. S1 in the online supplemental material). Note that we discuss the detection of wave reflection in more detail below (section 3b). In summary, waves that propagated upward over the North Pacific, were reflected downward when reaching the stratospheric Aleutian region. Although the zonal-mean diagnostics revealed no significant stratospheric anomalies (Fig. 2), our results thus indicate that the polar vortex indirectly (via wave reflection) contributed to the North Pacific blocking (Fig. 1b) causing the cold spell over North America.

\section{(ii) Event 2: The North American cold spell in February 2018}

Before the second North American cold spell (event 2), both the vortex strength, as well as the zonal-mean vertical heat fluxes were rather neutral, and also the NAM index remained positive in the stratosphere (Fig. 3). The longitudinal distribution of wave activity fluxes before and during event 2 (Fig. 5), however, showed similar spatial characteristics as for event 1 (Fig. 4). Approximately nine days before the event start, upward wave activity fluxes into the stratosphere were observed over large parts of Eurasia and the North Pacific (Figs. 5a,b). As for event 1, the Aleutian high at stratospheric levels above $10 \mathrm{~km}$ then reflected these waves downward over Canada (Figs. 5a,b). The occurrence of reflection is again confirmed by the 


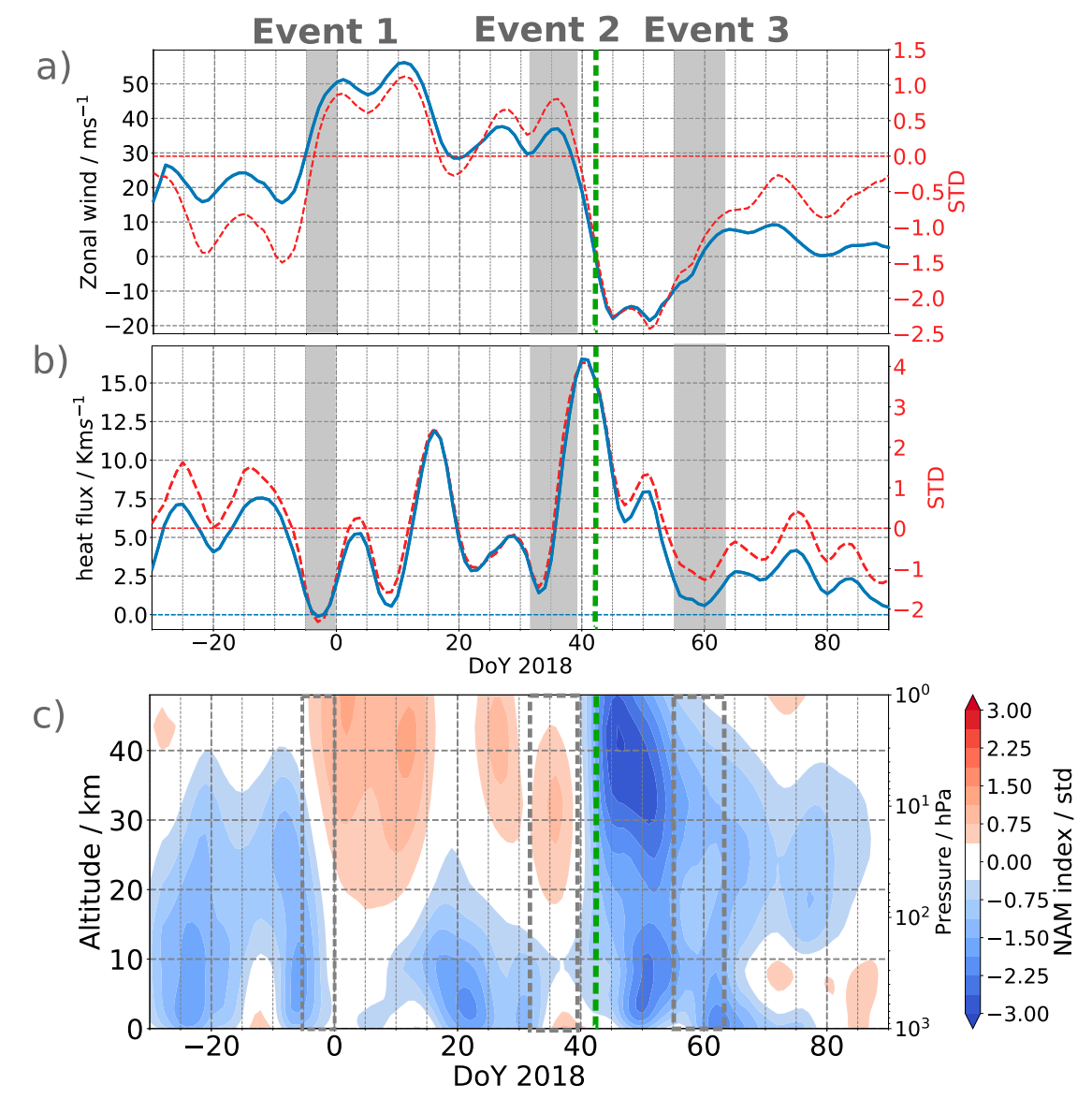

FIG. 3. Evolution of different zonal-mean indices in the winter 2017/18. (a) Time series of the stratospheric polar vortex strength calculated as the zonal-mean zonal wind at $60^{\circ} \mathrm{N}$ and at $10 \mathrm{hPa}$. Shown are the absolute values (blue line) and the standardized index (red dashed line). (b) Time series of the meridional heat flux averaged between $45^{\circ}$ and $75^{\circ} \mathrm{N}$ at $100 \mathrm{hPa}$. (c) Evolution of the northern annular mode (NAM) for different vertical levels. In all panels, the green dashed line indicates the SSW.

zonal mean EP flux (Edmon et al. 1980), indicating downward propagation below $20 \mathrm{~km}$ and northward of $60^{\circ} \mathrm{N}$ (see Fig. S1). Shortly after, roughly 4 days before the onset of event 2 , the upward and downward wave propagation intensified (Figs. $5 \mathrm{c}, \mathrm{d}$ ) and the positive eddy geopotential heights descended to the troposphere (Figs. 5c,e). This resulted in the observed North Pacific blocking during the event (Fig. 1). Note that compared to event 1 , the patterns of eddy geopotential heights and of vertical wave activity fluxes are slightly eastward shifted (Figs. 4 and 5), consistent with the resulting eastward shifted North Pacific blocking pattern during event 2 (Fig. 1).

Although both event 1 and event 2 were associated with downward reflected waves over Canada there were still pronounced differences between the events. In particular, the zonal-mean lower-stratospheric wave activity was overall much stronger during event 2 than during event 1 (Fig. 2b). Moreover, in contrast to event 1, enhanced hemisphere-wide wave activity fluxes reaching also higher-stratospheric levels shortly before but also during event 2 were observed (Figs. 5c,e). Thus, while stratosphere-troposphere coupling during event 1 was predominantly characterized by downward reflected waves leading to North Pacific blocking, event 2 was both associated with wave reflection over the North Pacific and Canada but at the same time also with enhanced wave activity fluxes entering higher-stratospheric levels thereby disturbing the vortex.

\section{(iii) Event 3: The European cold spell in February/ March 2018}

Directly after event 2 , the lower-stratospheric zonalmean heat flux was strongly enhanced ( $>4$ std; Fig. 3b), and also the height-longitude cross sections of the wave activity flux reveal upward fluxes across the hemisphere 


\section{Event 1}

a)

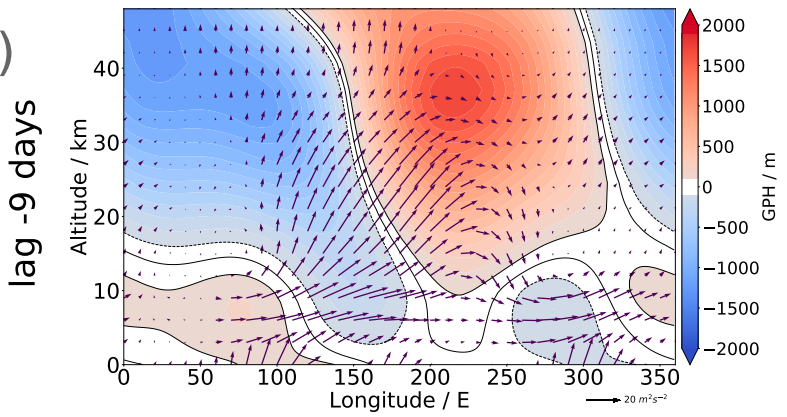

c)

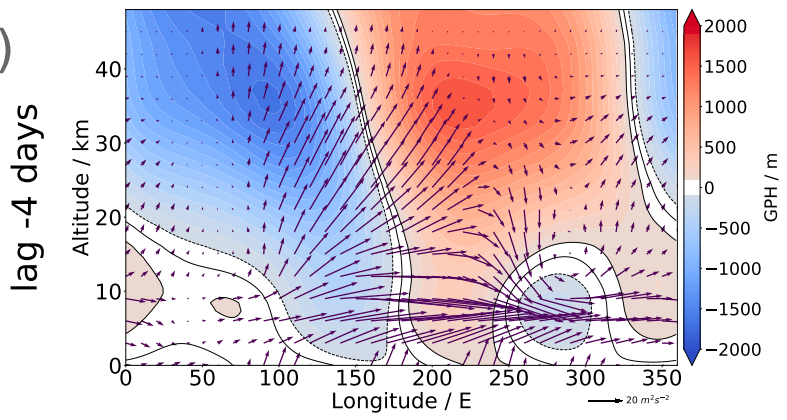

e)

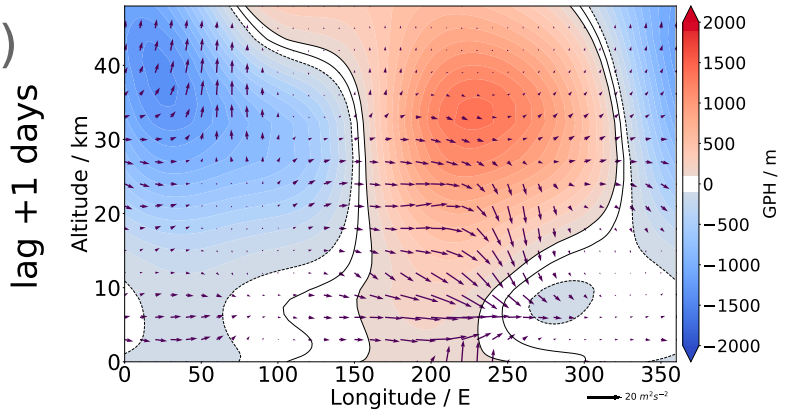

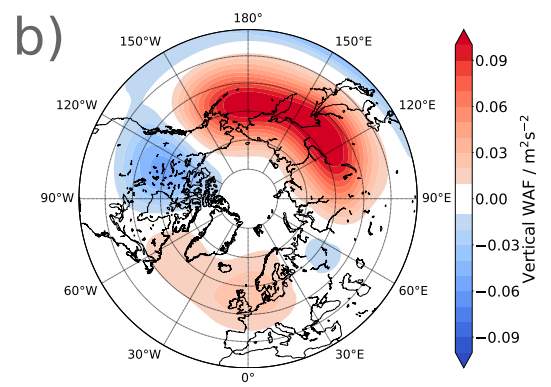

d)

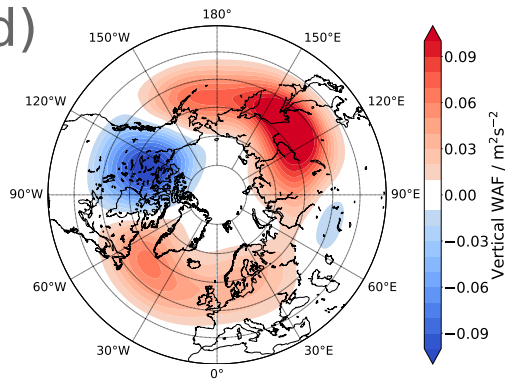

f)

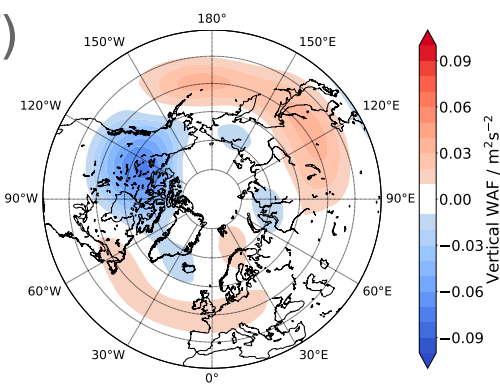

FIG. 4. Height-longitude cross sections of eddy geopotential heights (GPH, shading) and of wave activity fluxes (WAF, arrows) both averaged over $60^{\circ}-70^{\circ} \mathrm{N}$, (a) 9 days before, (c) 4 days before, and (e) 1 day after the onset of event 1 . Contour lines are shown at $-100,0$, and $100 \mathrm{~m}$ eddy geopotential height to highlight the vertical tilt of ridges and troughs. (b),(d),(f) As in (a),(c),(e), but for the vertical component of the wave activity flux at $100 \mathrm{hPa}$. Note that all quantities have been filtered for wave 1-3 components and a 3-day mean smoothing average has been applied (see section 2).

(Figs. 6a,b). This caused a drastic weakening of the stratospheric flow, resulting in easterly stratospheric winds starting on February 12, and thus a major SSW developed (see dashed green line in Fig. 3) as discussed already by previous studies (Karpechko et al. 2018; Lee et al. 2019). Consistent with the decelerated stratospheric flow (Fig. 3a), the stratospheric geopotential heights in the polar cap increased, represented by the overall weakened eddy geopotential heights (Fig. 6a). Further, also the NAM index became negative, with the most pronounced anomalies descending from the stratosphere down to the troposphere (Fig. 3c). Subsequently, 4 days before event 3 , wave fluxes remained upward over Canada but overall decreased in intensity (Figs. 6cf), allowing the vortex to slowly recover (Fig. 3a). This is largely consistent with a downward-propagating negative NAM, as discussed in several studies (Baldwin and Dunkerton 2001; Hitchcock and Simpson 2014), respectively, the notion of absorbing SSWs (Kodera et al. 2016).

In summary, the European cold spell (event 3) can thus directly be related to the major SSW that occurred shortly before. The SSW, caused by enhanced upward wave activity fluxes absorbed in the stratosphere, was followed by a negative NAM at stratospheric and tropospheric levels (Fig. 3c), coinciding with event 3. Thus, the reversal of stratospheric winds in mid-February can explain the formation of the pronounced North Atlantic blocking pattern (Fig. 1) and the associated cold spell over Europe later that month (Fig. 2c), being well in 


\section{Event 2}
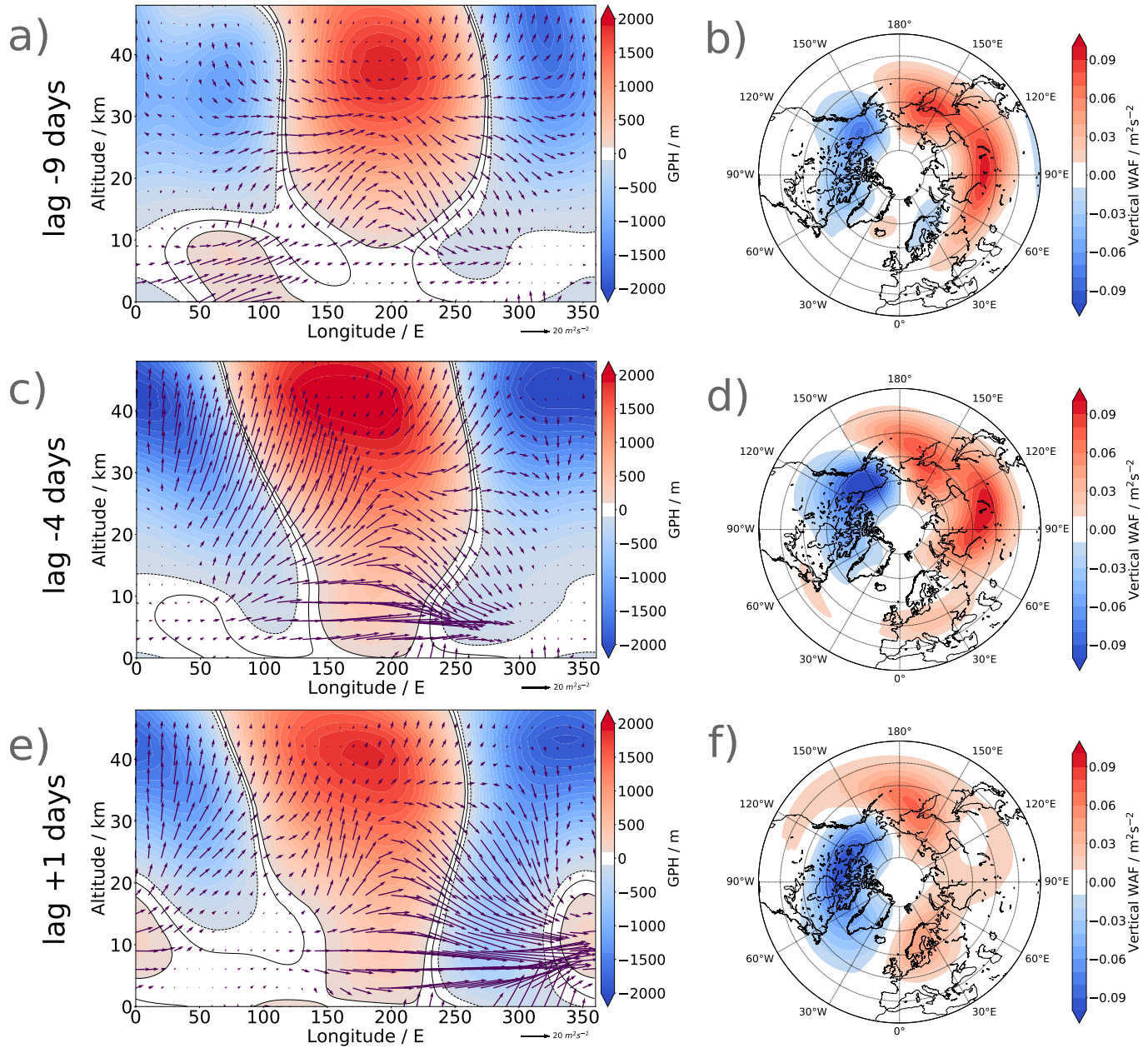

FIG. 5. As in Fig. 4, but for event 2.

agreement with several previous studies (e.g., Karpechko et al. 2017; Hitchcock and Simpson 2014; Kretschmer et al. 2018a; Kodera et al. 2016).

\section{b. Wave reflection in the stratosphere and its impacts on cold spells}

\section{1) Challenges to diagnose wave REFLECTION EVENTS}

The analyses of the evolution of daily wave activity fluxes during winter 2017/18 revealed that wave reflection played a major role for the cold spells over North America that winter (event 1 and 2). Yet, in contrast to the SSW associated with event 3 , the occurrence of wave reflection before event 1 and event 2 , are not evident when considering the temporal evolution of standard zonal-mean based indices only, such as the zonal-mean zonal wind or the phase of the NAM (Fig. 3). Previous studies proposed different indices and criteria to describe favorable stratospheric conditions for wave reflection (Perlwitz and Harnik 2003; Shaw et al. 2010; Nath et al. 2014; Kodera et al. 2008, 2013). As we discuss below using the example of winter 2017/18, detecting the exact timing and location of wave reflection remains, however, difficult.

Perlwitz and Harnik (2003) proposed a simple reflection index $\bar{U}_{2-10}$ indicating a reflective (negative) or nonreflective (positive) basic state of the polar vortex for a considered winter. For the winter 2017/18 (DJFM) this index is 6.6, suggesting a nonreflective basic state, inconsistent with the detected wave reflection events associated with event 1 and 2 . While the daily resolved $\bar{U}_{2-10}$ index [see Fig. 7a; Nath et al. (2016)] is indeed negative before and during event 2 (i.e., suggestive of a reflective state), it is positive for event 1 and thus misses the associated reflection event. However, this index is 


\section{Event 3}
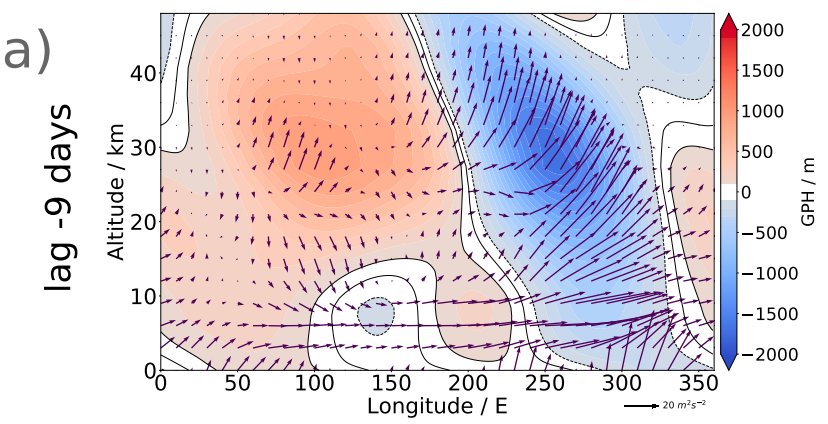

C)
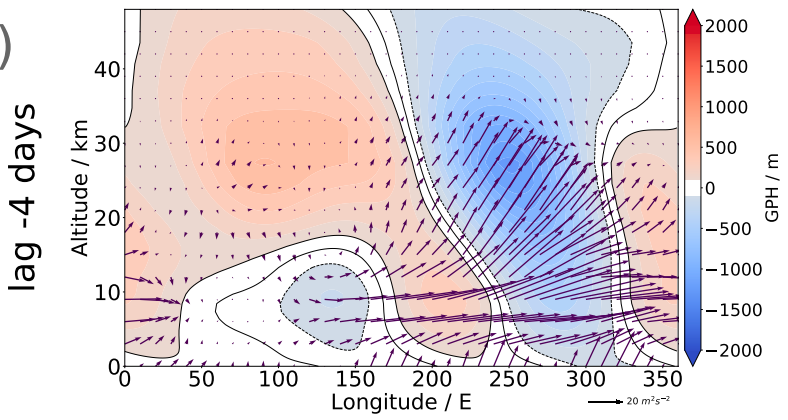

e)

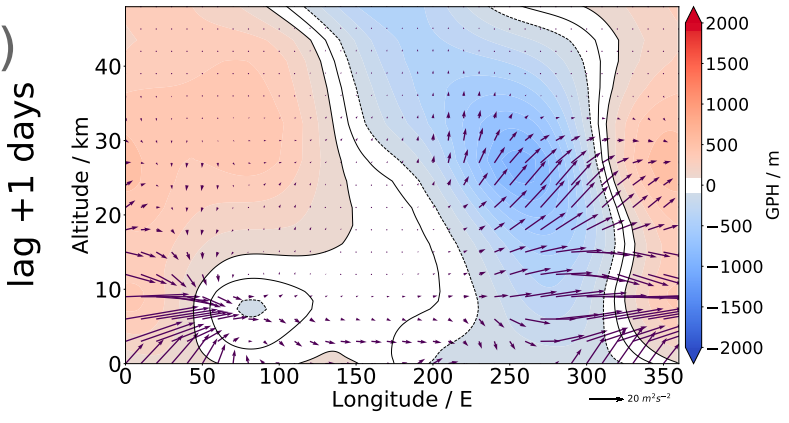

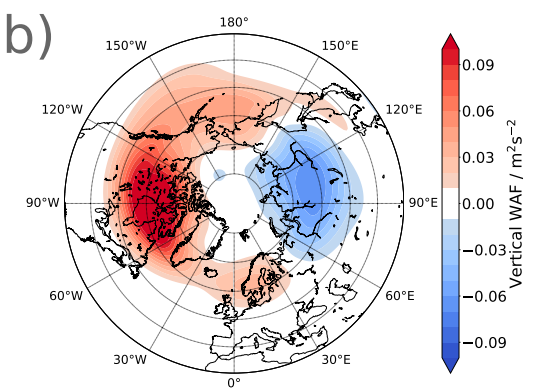

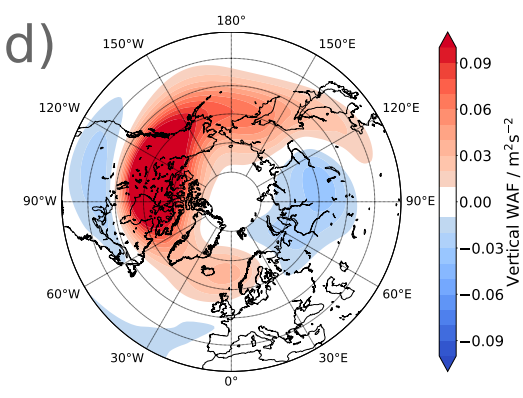

f)

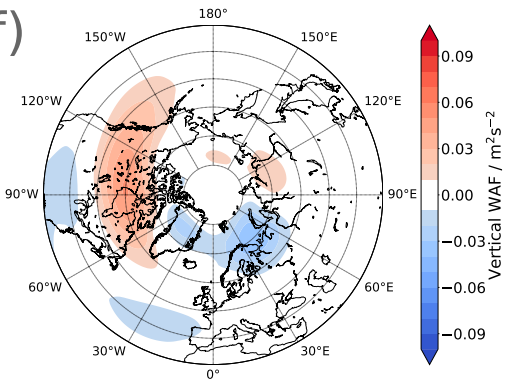

Fig. 6. As in Fig. 4, but for event 3.

also negative during the SSW in February 2018, such that it is generally not suitable to distinguish between SSWs and wave reflection (Harnik 2009). The daily and longitudinally resolved version of the $U_{2-10}$ index (Nath et al. 2016) is shown in Fig. 7b for the winter 2017/18. Before event 1 , this index is negative between $210^{\circ}$ and $260^{\circ} \mathrm{E}$, thus, approximately in the area where the wave reflection took place (Fig. 4). Further, it shows negative values in this region before and during event 2 . Hence, regionally resolved vertical wind shear can indeed help to detect wave refelction, consitent with Nath et al. (2014). Nevertheless, the negative values during SSWs remain as an issue (Fig. 7b), making it rather impractical to analyze intraseasonal variability of the polar vortex.

While the $\bar{U}_{2-10}$ index was introduced as a crude measure to classify seasons in reflective and nonreflective states, Perlwitz and Harnik (2003) described necessary wind conditions for wave reflection in more detail. First, the formation of a vertical reflective layer is required, shown by increased curvature in the vertical profile of the zonal-mean zonal wind at polar latitudes. Second, a meridional waveguide is needed. This is present if a second wind maximum in the zonal-mean zonal wind at polar latitudes forms, resulting in increased curvature in the meridional profile of the zonal-mean zonal wind at middle and polar latitudes between 30 and $5 \mathrm{hPa}$ (Perlwitz and Harnik 2003). In Fig. 8 we show the vertical (Figs. 8a,b) and meridional (Figs. 8c,d) zonal-mean zonal wind profile 4 days before event 1 and 2 (blue solid lines) as well as their seasonal climatologies (blue dashed lines). Motivated by the detected longitudinal variations (Fig. 7), we further plot the wind profiles averaged over the region $200^{\circ}-250^{\circ} \mathrm{E}$ (orange lines in Fig. 8), thus the region where the waves were reflected downward (Figs. 4 and 5). Increased curvatures (see section 2) in the wind profile are indicated by gray dots. 


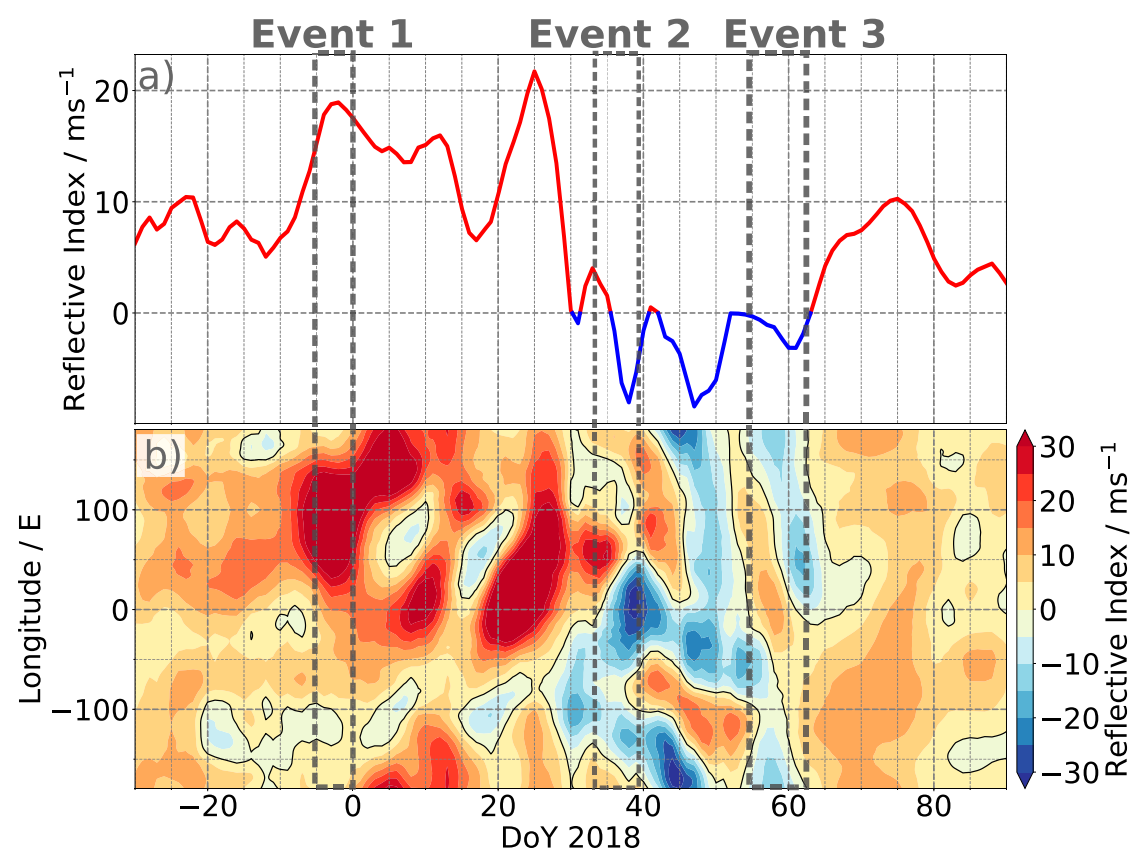

FIG. 7. (a) Reflective index $\bar{U}_{2-10}$ as defined by Perlwitz and Harnik (2004) but calculated for each day. (b) As in (a), but longitudinally resolved $U_{2-10}$ (see Nath et al. 2014).

The vertical profiles of the zonal-mean (blue) and regional-mean (orange) zonal winds before event 1 are different in structure and magnitude (Fig. 8a). The zonal-mean flow is below average and shows no strong curvature, though there is negative wind shear at $40 \mathrm{~km}$. In contrast, the regional profile shows indeed negative shear and strong curvature between 30 and $40 \mathrm{~km}$ as well as close to average zonal winds, and resembles the
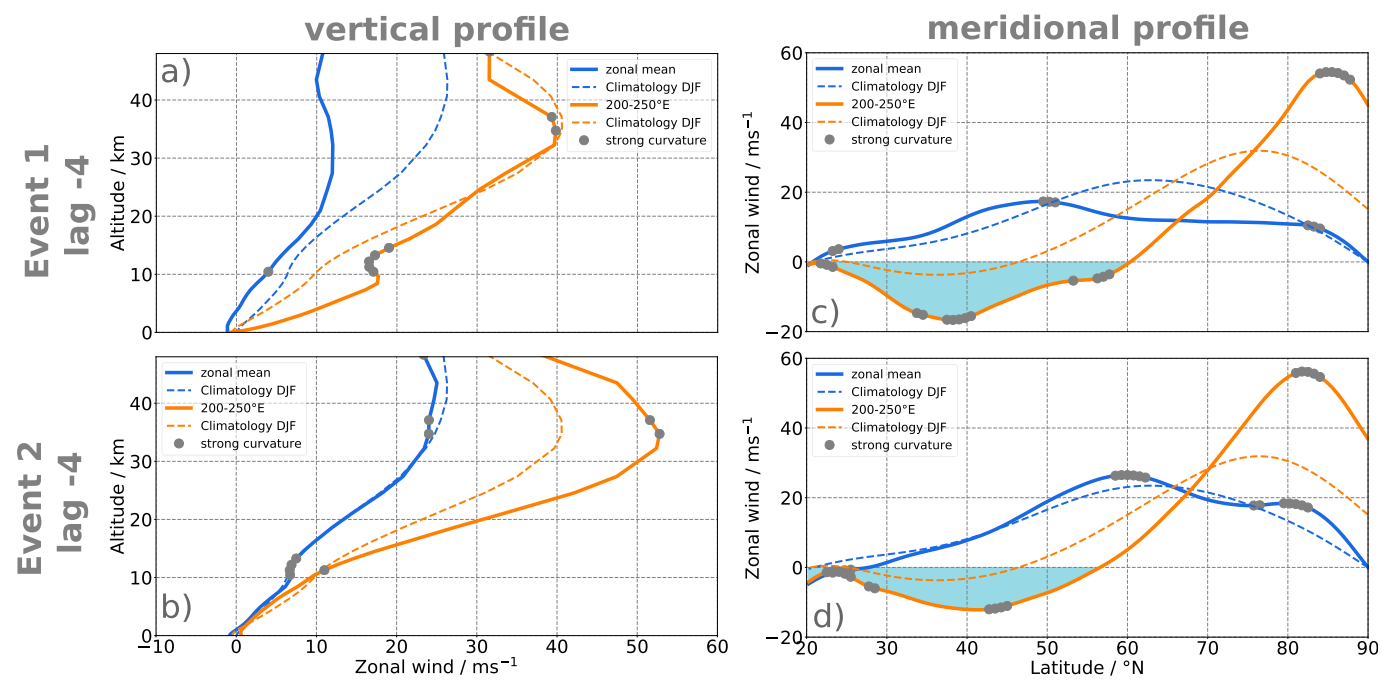

FIG. 8. (a) Vertical profiles of the 3-day mean zonal-mean zonal wind averaged between $70^{\circ}$ and $80^{\circ} \mathrm{N}$ (solid blue line) during event 1 and its winter (DJF) climatology (dashed blue line) as well as the regional-mean (averaged between $200^{\circ}$ and $250^{\circ} \mathrm{E}$ ) vertical profile (solid orange line) and its winter climatology (dashed orange line). (b) As in (a), but for event 2. (c) Meridional profiles (solid blue line) and its winter climatology (dashed blue line) of the 3 -day mean zonal-mean zonal wind at $30 \mathrm{hPa}$ as well as the regional-mean (averaged between $200^{\circ}$ and $250^{\circ} \mathrm{E}$ ) meridional profile (solid orange line) and its winter climatology (dashed orange line). The area of regional negative zonal wind is highlighted by blue shading. (d) As in (c), but for event 2. In all plots, gray dots mark levels where the curvature is above avarage (see section 2). 

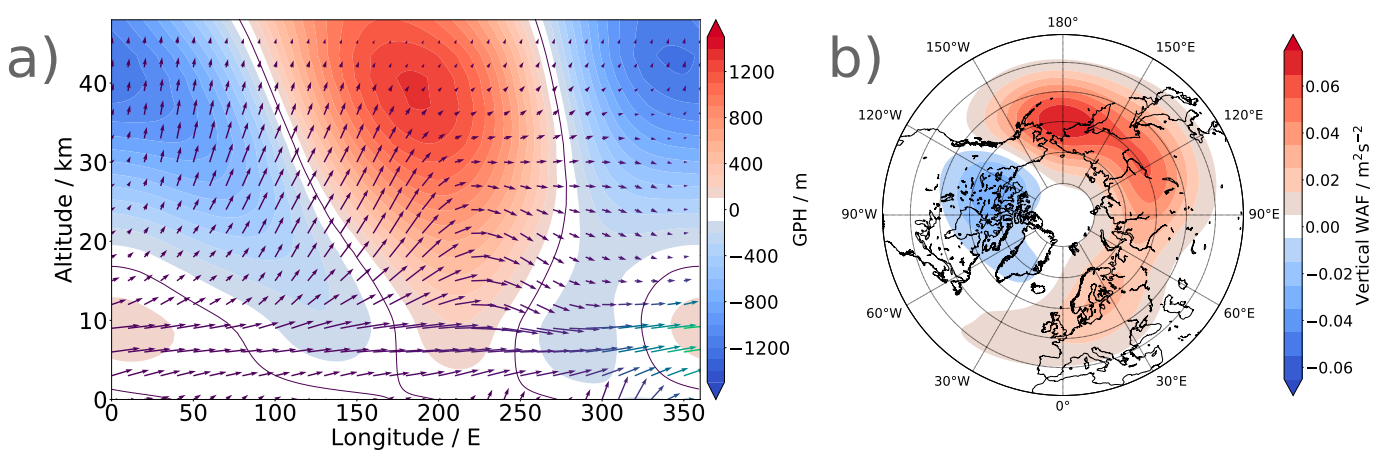

FIG. 9. (a) Composite of the height-longitude cross sections of eddy geopotential heights (shading) and of wave activity fluxes (arrows), averaged over $60^{\circ}-70^{\circ} \mathrm{N}$ during the 41 reflection events (defined as consecutive days when $\mathrm{RI}_{\mathrm{NP}}>1.5$, see section 3b). (b) As in (a), but for the vertical component of the wave activity flux at $100 \mathrm{hPa}$.

reflective vertical profile described in Perlwitz and Harnik (2003). The meridional profile (Fig. 8c) reveals increased curvature at mid and polar latitudes in both the zonal-mean (blue) and the regional mean (orange), with the latter being more pronounced. This is thus indicative of a waveguide between $50^{\circ}$ and $80^{\circ} \mathrm{N}$, needed for downward wave coupling but missing in the climatological mean meridional profile. Consistently, also the wind profiles associated with event 2 show increased curvature in the stratosphere (in both the zonal-mean and the regional mean, Fig. $8 \mathrm{~b}$ ) and indicate a meridional waveguide between $60^{\circ}$ and $80^{\circ} \mathrm{N}$ (Fig. $8 \mathrm{~d}$ ). Overall, these diagnostics thus confirm the occurrence of wave reflection associated with event 1 and 2 . Furthermore, it highlights that considering zonal means only can miss partially reflective stratospheric states (Fig. 8a).

\section{2) A NOVEL REGIONAL REFLECTION INDEX}

Given that existing wave reflection diagnoses either failed in detecting the 2017/18 events or could not differentiate between wave reflection and an SSW, we here suggest a new regional reflection index, $\mathrm{RI}_{\mathrm{NP}}$, to detect wave reflection events over the North Pacific. It is defined as the difference between the standardized meridional eddy heat flux over Siberia $\left(120^{\circ}-185^{\circ} \mathrm{E}\right)$ and Canada $\left(225^{\circ}-300^{\circ} \mathrm{E}\right)$ averaged between $45^{\circ}$ and $75^{\circ} \mathrm{N}$ at $100 \mathrm{hPa}$ :

$$
\mathrm{RI}_{\mathrm{NP}}=\left(v^{\prime} T^{\prime}\right)_{\mathrm{Sib}}^{\star}-\left(v^{\prime} T^{\prime}\right)_{\mathrm{Can}}^{\star}
$$

Here, $v$ denotes the meridional wind, $T$ denotes temperature, the prime denotes the deviation from the zonal mean, and the asterisk indicate that the quantities have been standardized. A wave reflection event is defined as when the $\mathrm{RI}_{\mathrm{NP}}$ exceeds 1.5 during at least ten consecutive days. A total of 41 of such regionl reflection events are detected over the period 1980-2019, including the wave reflection events that accompanied the North American cold spells in the winter 2017/18 (events 1 and 2) as discussed below in more detail. By definition, these reflection events are thus linked to above average upward wave propagation over Siberia and simultanoues enhanced downward propgation over Canada. The regions for this index have been chosen based on the wave reflection events that preceded events 1 and 2 and on the findings of Kretschmer et al. (2018a), who showed that wave reflection in these regions strongly projects onto cold spells in North America.

To confirm the functionality of the new $\mathrm{RI}_{\mathrm{NP}}$ index, Fig. 9 shows, in accordance with Figs. 4 and 5, composites of the wave activity flux during all 41 detected reflection events. Indeed, the longitude-height profile reveals upward wave activity fluxes into the stratosphere over Eurasia and the North Pacific sector, which are reflected downward around the Aleutian heigh between 10 and $25 \mathrm{~km}$, as well as downward wave propagation over Canada (Fig. 9a). Moreover, by construction, the vertical component of the wave activity flux at $100 \mathrm{hPa}$ shows upward propagation over Eurasia and downward propagation over Canada (Fig. 9b). Thus, our regional reflective index based on meridional eddy-heat fluxes at $100 \mathrm{hPa}$ is suitable to detect reflecting events.

In the following we are foremost interested if the proposed regional reflection index $\mathrm{RI}_{\mathrm{NP}}$ is also associated with cold spells over North America, as suggested by the present analysis. In this context, we first show (see Fig. 10) the temporal evolution of $\mathrm{RI}_{\mathrm{NP}}$ over the winter 2017/18 (red), together with the standardized blocking index over the North Pacific $\left(150^{\circ}-230^{\circ} \mathrm{E}\right.$, green), and the temperature anomalies over northeastern North America $\left(40^{\circ}-60^{\circ} \mathrm{N}, 260^{\circ}-290^{\circ} \mathrm{E}\right.$, blue $)$. As expected, the $\mathrm{RI}_{\mathrm{NP}}$ is strongly increased before events 1 and 2 and peaks approximately one week before the events started. Furthermore, North Pacific blocking is detected and the temperatures drop during the events (cf. to Figs. 1 and 2). During the SSW at the end of February 2018 


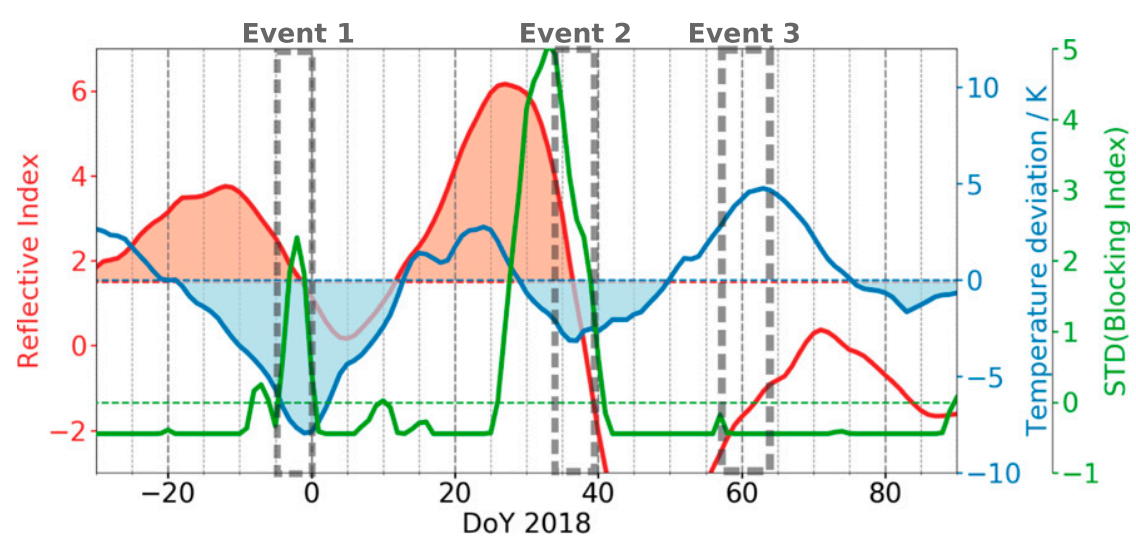

FIG. 10. Evolution of the regional reflective index $\mathrm{RI}_{\mathrm{NP}}$ (in red), surface temperature anomalies over northeastern North America $\left(40^{\circ}-60^{\circ} \mathrm{N}, 260^{\circ}-290^{\circ} \mathrm{E}\right.$, in blue), and the North Pacific blocking index (calculated over $150^{\circ}-230^{\circ} \mathrm{E}$, in green) over the course of the winter 2017/18.

associated with event 3 , the regional reflection index $R I_{N P}$ is negative, hence not indicating wave reflection, in contrast to the $U_{2-10}$ index (see Fig. 7 but note the different sign of the indices). Thus, for the winter 2017/18 the index meets our requirements.

To test if these findings can be generalized, we next plot the composites of the same indices during all 41 detected reflecting events (Fig. 11a, see supplement for individual winters). Lag zero marks the first day where the reflective index $\mathrm{RI}_{\mathrm{NP}}$ is equal or above the threshold of 1.5 (red dashed line in Fig. 11). Approximately a week after the detection of wave reflection (red shaded area), the North Pacific blocking index becomes positive (green line) and also temperature anomalies in North America become negative (blue shaded area). Hence, these findings support the occurrence of wave reflection to favor North Pacific blocking associated with cold spells over North America, was shown by previous studies (e.g., Kodera et al. 2008).

Previous studies further noted, however, that the effect of wave reflection on surface weather strongly depends on the state of the tropospheric circulation (Kodera et al. 2013). Therefore, to study this aspect in more detail, we next divide the 41 reflection events into those where the temperature anomalies over North America were positive during the event start (25 events, Fig. 11b) and those where they were already negative (16 events, Fig. 11c). For both event types the blocking index peaks approximately 5 to 7 days after the reflective index but was negative during the event start. For the former event type, the mean temperature anomalies then switch to negative as a result of the occurring Pacific blocking (Fig. 11b). For the latter type the temperature deviation become more pronounced and remain negative for several weeks after (Fig. 11c).
Overall, these results are thus supportive of a connection between wave reflection and North Pacific blocking respectively cold spells over North America, consistent with previous findings (Kodera et al. 2013; Kretschmer et al. 2018a). Our analysis also suggests that reflection events cannot only deepen and prolong a cold spell in the troposphere (Fig. 11c) but can even trigger such an event (Fig. 11b). Furthermore, the detected effect of wave reflection on tropospheric circulation includes a time lag of approximately one week, indicating the potential to predict cold spells as well as its persistence.

\section{Discussion}

Consistent with previous studies we showed that different stratosphere-troposphere coupling mechanisms result in regionally different surface impacts over Eurasia and North America. Our case study of the winter 2017/18 further highlights that wave reflection and major SSWs linked to wave absorption can happen in the same season, and even in short succession as shown for event 2 and 3 . Thus, seasonal-mean indices to classify the winter polar vortex as reflecting or absorbing respectively strong or weak (Perlwitz and Harnik 2003), will miss these different events as well as their surface impacts. Moreover, our results show that wave reflection can occur regionally, supporting the notion of a partially reflecting surface (Nath et al. 2014). Zonal-mean diagnostics are therefore likely to miss these events. Here we focused on reflection occurring over North America, but previous studies also documented wave reflection over Eurasia (Kodera and Mukougawa 2017).

Previous studies indicated that not only the strength but also the temporal length of the upward wave pulse plays an important role for whether wave reflection or 

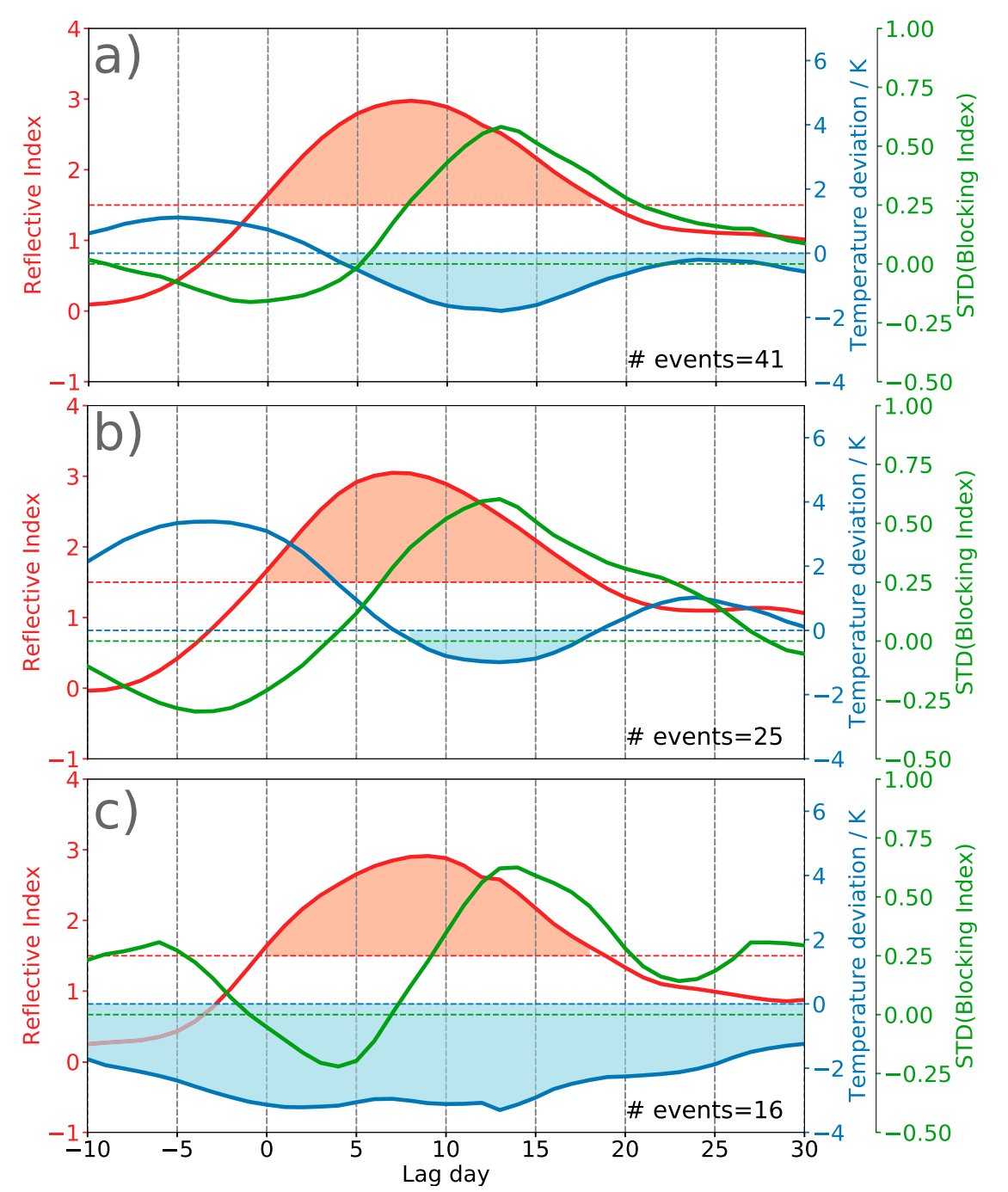

FIG. 11. As in Fig. 10, but averaged over (a) all detected reflecting events, (b) those reflecting events for which the event start coincided with positive North American temperature anomalies, and (c) those coinciding with negative temperature anomalies. In all panels, lag 0 denotes the start date of the reflection events.

an SSW to occur (Harnik 2009; Kodera et al. 2016; Kretschmer et al. 2018a). In this context, it was proposed that persistently enhanced upward wave activity fluxes are linked to major SSWs, while shorter pulses of only a few days are predominantly associated with wave reflection. Our results are generally supportive of this statement. While strongest and most persistent fluxes were found before and during event 2 (i.e., before the SSW), the first event was linked to a short period of enhances wave activity (Fig. 3b). Nevertheless, results for event 2 show that reflection can occur during the wave pulse leading to a SSW, indicating once more the individual characteristics of each major SSW (Tripathi et al. 2015). Overall, it remains thus an important task to better understand the atmospheric conditions leading to wave reflection and absorption. Here we restricted ourselves in analyzing the influence of the polar vortex on the occurrence of high-latitude blocking. However, it is also well known that stratospheric variability can be influenced by tropospheric preconditions (Martius et al. 2009; Cohen and Jones 2011; Smith et al. 2010). For example, SSWs have been shown to be often preceded by blocking in the Ural Mountain region, which via constructive interference with the climatological wave can lead to persistent phases of enhanced vertical wave activity (Kretschmer et al. 2016; Feldstein and Lee 2014). Here we also detected blocking in this region just before event 2 (Fig. 1), associated with the cold temperatures in eastern Siberia (Fig. 2b), consistent with previous SSWs (Lehtonen and Karpechko 2016). 
In contrast, wave reflection over the North Pacific has been related to high pressure systems in the North Atlantic, triggering a wave train into the stratosphere (Kodera et al. 2013). In agreement with this hypothesis, we find blocking around the null-meridian before event 1 and event 2 as well as a wave train stretching from western Eurasia (around $50^{\circ} \mathrm{E}$ ) into the stratospheric Aleutians. Nevertheless, a more comprehensive analysis is required to assess this relationship. This includes assessing the role of the horizontal convergence of wave activity fluxes as well as a better understanding of the interactions of planetary and synoptic waves in the troposphere during wave reflection events. Moreover, to what extent for example the phase of the quasi-biennial oscillation (QBO; Watson and Gray 2014) or tropical Pacific variability (Polvani et al. 2017; Garfinkel and Hartmann 2008; Domeisen et al. 2019; Barnes et al. 2019) have been favorable for the occurrence of the midlatitude cold spells in the winter 2017/18 is further important to understand, but was beyond the scope of this study. Disentangling the interplay and relative contribution of these teleconnection pathways is an important step toward improved understanding and prediction of winter weather and climate.

\section{Summary and conclusions}

Based on spatiotemporal analyses of different stratospheric wave diagnostics, we showed that the two severe North American cold spells (event 1 and event 2) that occurred in the winter 2017/18 were associated with high-latitude blocking over the North Pacific. Our analysis further revealed that downward reflected planetary waves by the stratospheric polar vortex over Canada led to the blocking. In contrast, the European cold spell at the end of the winter (event 3) was related to blocking in the North Atlantic, resulting from a major SSW and a downward-propagating negative NAM from the stratosphere. Overall, stratosphere-troposphere coupling thus played a central role, both directly (associated with the SSW) and indirectly (associated with the downward reflected waves), for the occurrence of the midlatitude cold spells in this winter.

Our results further suggest that previously proposed indices (Perlwitz and Harnik 2004; Harnik and Lindzen 2001) based on zonal-mean diagnostics to detect wave reflection are too limited to capture these rather regional reflection events and their impacts. Here, we proposed a novel regional reflective index, capturing wave reflection events over the North Pacific, associated with tropospheric blocking in this area and cold temperatures over North America. Given the involved time lag of approximately one week, this index has the potential to improve forecasts of North American cold spells associated with stratospheric wave reflection.

We suggest that future studies on the stratospheric influence on tropospheric circulation should not only be restricted to studying the drivers and impacts of SSWs but should further consider the role of wave reflection. Evaluating the representation of individual wave reflection events in operational forecast models will give new insight in this context and will be important to assess their predictability. Overall, a better understanding of stratosphere-troposphere coupling, including its regional drivers and impacts is essential and can pave the way for improved S2S predictions of winter weather in the midlatitudes.

Acknowledgments. We thank ECMWF for making the ERA-Interim data available. M.K. was supported by the German Federal Ministry of Education and Research, Grant 01LN1304A. We also thank Daniela Domeisen for helpful discussions and the anonymous reviewer for their very constructive comments that improved this study.

\section{REFERENCES}

Analitis, A., and Coauthors, 2008: Effects of cold weather on mortality: Results from 15 European cities within the PHEWE project. Amer. J. Epidemiol., 168, 1397-1408, https://doi.org/ 10.1093/aje/kwn266.

Baldwin, M. P., and T. J. Dunkerton, 2001: Stratospheric harbingers of anomalous weather regimes. Science, 294, 581-584, https://doi.org/10.1126/science.1063315.

—, and D. W. Thompson, 2009: A critical comparison of stratosphere-troposphere coupling indices. Quart. J. Roy. Meteor. Soc., 135, 1661-1672, https://doi.org/10.1002/qj.479.

Barnes, E. A., S. M. Samarasinghe, I. Ebert-Uphoff, and J. C. Furtado, 2019: Tropospheric and stratospheric causal pathways between the MJO and NAO. J. Geophys. Res. Atmos. 124, 9356-9371, https://doi.org/10.1029/2019JD031024.

Baxter, S., and S. Nigam, 2015: Key role of the North Pacific Oscillation-West Pacific pattern in generating the extreme 2013/14 North American winter. J. Climate, 28, 8109-8117, https://doi.org/10.1175/JCLI-D-14-00726.1.

Butler, A. H., L. M. Polvani, and C. Deser, 2014: Separating the stratospheric and tropospheric pathways of El Niño-Southern Oscillation teleconnections. Environ. Res. Lett., 9, 024014, https://doi.org/10.1088/1748-9326/9/2/024014.

Chen, X., and D. Luo, 2017: Arctic sea ice decline and continental cold anomalies: Upstream and downstream effects of Greenland blocking. Geophys. Res. Lett., 44, 3411-3419, https://doi.org/10.1002/2016GL072387.

Cohen, J., and J. Jones, 2011: Tropospheric precursors and stratospheric warmings. J. Climate, 24, 6562-6572, https:// doi.org/10.1175/2011JCLI4160.1.

— , and Coauthors, 2014: Recent Arctic amplification and extreme mid-latitude weather. Nat. Geosci., 7, 627-637, https:// doi.org/10.1038/ngeo2234.

_, K. Pfeiffer, and J. A. Francis, 2018: Warm Arctic episodes linked with increased frequency of extreme winter weather in 
the United States. Nat. Commun., 9, 869, https://doi.org/ 10.1038/s41467-018-02992-9.

Dee, D. P., and Coauthors, 2011: The ERA-Interim reanalysis: Configuration and performance of the data assimilation system. Quart. J. Roy. Meteor. Soc., 137, 553-597, https:// doi.org/10.1002/qj.828.

Domeisen, D. I. V., C. I. Garfinkel, and A. H. Butler, 2019: The teleconnection of El Niño Southern Oscillation to the stratosphere. Rev. Geophys., 57, 5-47, https://doi.org/10.1029/ 2018RG000596.

Dunn-Sigouin, E., and T. A. Shaw, 2015: Comparing and contrasting extreme stratospheric events, including their coupling to the tropospheric circulation. J. Geophys. Res. Atmos., 120, 1374-1391, https://doi.org/10.1002/2014JD022116.

Edmon, H. J., B. J. Hoskins, and M. E. McIntyre, 1980: EliassenPalm cross sections for the troposphere. J. Atmos. Sci., 37, 2600-2616, https://doi.org/10.1175/1520-0469(1980)037<2600: EPCSFT $>2.0 . \mathrm{CO} ; 2$.

Feldstein, S. B., and S. Lee, 2014: Intraseasonal and interdecadal jet shifts in the Northern Hemisphere: The role of warm pool tropical convection and sea ice. J. Climate, 27, 6497-6518, https://doi.org/10.1175/JCLI-D-14-00057.1.

Garfinkel, C. I., and D. L. Hartmann, 2008: Different ENSO teleconnections and their effects on the stratospheric polar vortex. J. Geophys. Res., 113, D18114, https://doi.org/10.1029/ 2008JD009920.

— , S. W. Son, K. Song, V. Aquila, and L. D. Oman, 2017: Stratospheric variability contributed to and sustained the recent hiatus in Eurasian winter warming. Geophys. Res. Lett., 44, 374-382, https://doi.org/10.1002/2016GL072035.

Handorf, D., R. Jaiser, K. Dethloff, A. Rinke, and J. Cohen, 2015: Impacts of Arctic sea ice and continental snow cover changes on atmospheric winter teleconnections. Geophys. Res. Lett., 42, 2367-2377, https://doi.org/10.1002/2015GL063203.

Harnik, N., 2009: Observed stratospheric downward reflection and its relation to upward pulses of wave activity. J. Geophys. Res., 114, D08120, https://doi.org/10.1029/2008JD010493.

, and R. S. Lindzen, 2001: The effect of reflecting surfaces on the vertical structure and variability of stratospheric planetary waves. J. Atmos. Sci., 58, 2872-2894, https://doi.org/10.1175/ 1520-0469(2001)058<2872:TEORSO > 2.0.CO;2.

Hitchcock, P., and I. R. Simpson, 2014: The downward influence of stratospheric sudden warmings. J. Atmos. Sci., 71, 3856-3876, https://doi.org/10.1175/JAS-D-14-0012.1.

Karpechko, A. Y., P. Hitchcock, D. H. Peters, and A. Schneidereit, 2017: Predictability of downward propagation of major sudden stratospheric warmings. Quart. J. Roy. Meteor. Soc., 143, 1459-1470, https://doi.org/10.1002/qj.3017.

—, A. Charlton-Perez, M. Balmaseda, N. Tyrrell, and F. Vitart, 2018: Predicting sudden stratospheric warming 2018 and its climate impacts with a multimodel ensemble. Geophys. Res. Lett., 45, 13 538-13 546, https://doi.org/10.1029/2018GL081091.

Kidston, J., A. A. Scaife, S. C. Hardiman, D. M. Mitchell, N. Butchart, M. P. Baldwin, and L. J. Gray, 2015: Stratospheric influence on tropospheric jet streams, storm tracks and surface weather. Nat. Geosci., 8, 433-440, https://doi.org/10.1038/ngeo2424.

Kodera, K., and H. Mukougawa, 2017: Eurasian cold surges triggered by the nonlinear reflection of stratospheric planetary waves in December 2012. SOLA, 13, 140-145, https://doi.org/ 10.2151/sola.2017-026

,$- \ldots$, and S. Itoh, 2008: Trospheric impact of reflected planetary waves from the stratosphere. Geophys. Res. Lett., 35, L16806, https://doi.org/10.1029/2008GL034575.
,-- , and A. Fujii, 2013: Influence of the vertical and zonal propagation of stratospheric planetary waves on tropospheric blockings. J. Geophys. Res. Atmos., 118, 8333-8345, https:// doi.org/10.1002/jgrd.50650.

, _ - P. Maury, M. Ueda, and C. Claud, 2016: Absorbing and reflecting sudden stratospheric warming events and their relationship with tropospheric circulation. J. Geophys. Res. Atmos., 121, 80-94, https://doi.org/10.1002/2015JD023359.

Kolstad, E. W., T. Breiteig, and A. A. Scaife, 2010: The association between stratospheric weak polar vortex events and cold air outbreaks in the Northern Hemisphere. Quart. J. Roy. Meteor. Soc., 136, 886-893, https://doi.org/10.1002/qj.620.

Kretschmer, M., D. Coumou, J. F. Donges, and J. Runge, 2016: Using causal effect networks to analyze different arctic drivers of midlatitude winter circulation. J. Climate, 29, 4069-4081, https://doi.org/10.1175/JCLI-D-15-0654.1.

_ J. Cohen, V. Matthias, J. Runge, and D. Coumou, 2018a: The different stratospheric influence on cold-extremes in Eurasia and North America. npj Climate Atmos. Sci., 1, 44, https:// doi.org/10.1038/s41612-018-0054-4.

— D. Coumou, L. Agel, M. Barlow, E. Tziperman, and J. D. Cohen, 2018b: More-persistent weak stratospheric polar vortex states linked to cold extremes. Bull. Amer. Meteor. Soc., 99, 49-60, https://doi.org/10.1175/BAMS-D-16-0259.1.

Lee, S. H., A. J. Charlton-Perez, J. C. Furtado, and S. J. Woolnough, 2019: Abrupt stratospheric vortex weakening associated with North Atlantic anticyclonic wave breaking. J. Geophys. Res. Atmos., 124, 8563-8575, https://doi.org/ 10.1029/2019JD030940.

Lehtonen, I., and A. Y. Karpechko, 2016: Observed and modeled tropospheric cold anomalies associated with sudden stratospheric warmings. J. Geophys. Res. Atmos., 121, 1591-1610, https://doi.org/10.1002/2015JD023860.

Linkin, M. E., and S. Nigam, 2008: The North Pacific OscillationWest Pacific teleconnection pattern: Mature-phase structure and winter impacts. J. Climate, 21, 1979-1997, https://doi.org/ 10.1175/2007JCLI2048.1.

Martius, O., L. M. Polvani, and H. C. Davies, 2009: Blocking precursors to stratospheric sudden warming events. Geophys. Res. Lett., 36, L14806, https://doi.org/10.1029/2009GL038776.

Matsuno, T., 1971: A dynamical model of the stratospheric sudden warming. J. Atmos. Sci., 28, 1479-1494, https://doi.org/10.1175/ 1520-0469(1971)028<1479:ADMOTS > 2.0.CO;2.

Messori, G., R. Caballero, and M. Gaetani, 2016: On cold spells in North America and storminess in western Europe. Geophys. Res. Lett., 43, 6620-6628, https://doi.org/10.1002/2016GL069392.

Nath, D., W. Chen, L. Wang, and Y. Ma, 2014: Planetary wave reflection and its impact on tropospheric cold weather over Asia during January 2008. Adv. Atmos. Sci., 31, 851-862, https://doi.org/10.1007/s00376-013-3195-8.

,,-- C. Zelin, A. I. Pogoreltsev, and K. Wei, 2016: Dynamics of 2013 sudden stratospheric warming event and its impact on cold weather over Eurasia: Role of planetary wave reflection. Sci. Rep., 6, 24174, https://doi.org/10.1038/SREP24174.

Palmer, T., 2014: Record-breaking winters and global climate change. Science, 344, 803-804, https://doi.org/10.1126/science.1255147.

_, and J. A. Owen, 1986: A possible relationship between some "severe" winters in North America and enhanced convective activity over the tropical west Pacific. Mon. Wea. Rev., 114, 648-651, https://doi.org/10.1175/1520-0493(1986)114<0648: APRBSW $>2.0 . \mathrm{CO} ; 2$.

Perlwitz, J., and N. Harnik, 2003: Observational evidence of a stratospheric influence on the troposphere by planetary wave 
reflection. J. Climate, 16, 3011-3026, https://doi.org/10.1175/ 1520-0442(2003)016<3011:OEOASI $>2.0$. CO;2.

, and - 2004: Downward coupling between the stratosphere and troposphere: The relative roles of wave and zonal mean processes. J. Climate, 17, 4902-4909, https://doi.org/ 10.1175/JCLI-3247.1.

Pithan, F., and Coauthors, 2018: Role of air-mass transformations in exchange between the Arctic and mid-latitudes. Nat. Geosci., 11, 805-812, https://doi.org/10.1038/s41561-018-0234-1.

Plumb, R., 1985: On the three-dimensional propagation of stationary waves. J. Atmos. Sci., 42, 217-229, https://doi.org/ 10.1175/1520-0469(1985)042<0217:OTTDPO > 2.0.CO;2.

Polvani, L. M., and D. W. Waugh, 2004: Upward wave activity flux as a precursor to extreme stratospheric events and subsequent anomalous surface weather regimes. J. Climate, 17, 3548-3554, https://doi.org/10.1175/1520-0442(2004)017<3548:UWAFAA > 2.0.CO;2.

— L. Sun, A. H. Butler, J. H. Richter, and C. Deser, 2017: Distinguishing stratospheric sudden warmings from ENSO as key drivers of wintertime climate variability over the North Atlantic and Eurasia. J. Climate, 30, 1959-1969, https:// doi.org/10.1175/JCLI-D-16-0277.1.

Scaife, A. A., and Coauthors, 2016: Seasonal winter forecasts and the stratosphere. Atmos. Sci. Lett., 17, 51-56, https://doi.org/ 10.1002/asl.598.

Scherhag, R., 1952: Die explosionsartige Stratosphärenerwär-mung des Spätwinters. Ber. Dtsch. Wetterd., 38, 51-63.

Shaw, T. A., J. Perlwitz, and N. Harnik, 2010: Downward wave coupling between the stratosphere and troposphere: The importance of meridional wave guiding and comparison with zonal-mean coupling. J. Climate, 23, 6365-6381, https:// doi.org/10.1175/2010JCLI3804.1.

Sigmond, M., J. F. Scinocca, V. V. Kharin, and T. G. Shepherd, 2013: Enhanced seasonal forecast skill following stratospheric sudden warmings. Nat. Geosci., 6, 98-102, https://doi.org/ 10.1038/ngeo1698.

Smith, K. L., C. G. Fletcher, and P. J. Kushner, 2010: The role of linear interference in the annular mode response to extratropical surface forcing. J. Climate, 23, 6036-6050, https:// doi.org/10.1175/2010JCLI3606.1.

Tibaldi, S., and F. Molteni, 1990: On the operational predictability of blocking. Tellus, 42A, 343-365, https://doi.org/10.3402/ tellusa.v42i3.11882.

Tripathi, O. P., and Coauthors, 2015: The predictability of the extratropical stratosphere on monthly time-scales and its impact on the skill of tropospheric forecasts. Quart. J. Roy. Meteor. Soc., 141, 987-1003, https://doi.org/10.1002/qj.2432.

Vihma, T., 2014: Effects of Arctic sea ice decline on weather and climate: A review. Surv. Geophys., 35, 1175-1214, https:// doi.org/10.1007/s10712-014-9284-0.

Watson, P. A. G., and L. J. Gray, 2014: How does the quasi-biennial oscillation affect the stratospheric polar vortex? J. Atmos. Sci., 71, 391-409, https://doi.org/10.1175/JAS-D-13-096.1.

Waugh, D. W., A. H. Sobel, and L. M. Polvani, 2017: What is the polar vortex and how does it influence weather? Bull. Amer. Meteor. Soc., 98, 37-44, https://doi.org/10.1175/BAMS-D-15-00212.1.

Woollings, T., 2010: Dynamical influences on European climate: An uncertain future. Philos. Trans. Roy. Soc., 368A, 3733-3756, https://doi.org/10.1098/RSTA.2010.0040.

— , A. Charlton-Perez, S. Ineson, A. G. Marshall, and G. Masato, 2010: Associations between stratospheric variability and tropospheric blocking. J. Geophys. Res., 115, D06108, https:// doi.org/10.1029/2009JD012742.

Yao, Y., D. Luo, A. Dai, and I. Simmonds, 2017: Increased quasi stationarity and persistence of winter ural blocking and Eurasian extreme cold events in response to Arctic warming. Part I: Insights from observational analyses. J. Climate, 30, 3549-3568, https://doi.org/10.1175/JCLI-D-16-0261.1. 